\title{
ARTICLES
}

\section{Collaboration and Integration}

\author{
Embedding Library Resources in Canvas
}

Jennifer L. Murray and Daniel E. Feinberg

\section{ABSTRACT}

The University of North Florida (UNF) transitioned to Canvas as its Learning Management System (LMS) in summer 2017. This implementation brought on opportunities that allowed for a more userfriendly learning environment for students. Working with students in courses which were in-person, hybrid, or online, brought about the need for the library to have a place in the Canvas LMS. Students needed to remember how to access and locate library resources and services outside of Canvas. During this time, the Thomas G. Carpenter Library's online presence was enhanced, yet still not visible in Canvas. It became apparent that the library needed to be integrated into Canvas courses. This would enable students to easily transition between their coursework and finding resources and services to support their studies. In addition, librarians who worked with students, looked for ways for students to easily find library resources and services online. After much discussion, it became clear to the Online Learning Librarian (OLL) and the Director of Technical Services and Library Systems (Library Director) that the library needed to explore ways to integrate more with Canvas.

\section{INTRODUCTION}

Online learning is not a new concept at the UNF. In fact, in-person, hybrid, and online courses used online learning in some capacity since distance learning took hold in higher education. UNF transitioned to Canvas as their Learning Management System (LMS) in summer 2017, which replaced Blackboard. This change, which affected all the UNF's online instruction and student learning, brought on new benefits and challenges that allowed for a more secure system for students to take in-person, hybrid, and distance learning courses. While this change occurred, UNF's Library went through many changes in its virtual presence. Students, specifically those who had classes that utilized Canvas, needed a user-friendly way to use the library website and its resources virtually. In response, the library's resources transitioned into having a greater online presence. However, ultimately, many students needed to use resources that they did not actually realize were available electronically from the library. Through instruction and research consultations (both in-person and virtually), students needed to be directed back to the library homepage to access resources; however, the reality was that unless there was a presence of library instruction or professors pointing out library resources, students instead turned to Google or other easy to find online resources to which they were previously exposed.

\section{HOW THE PROJECT ORIGINATED}

By spring 2018, there was growth of UNF courses that were converted to online or hybrid courses. As students used Canvas more, librarians started receiving feedback from in-person and online sessions that students had difficulty accessing the library's resources while in Canvas. The lack of library visibility in Canvas caused the librarians to truly acknowledge that this was a problem.

Jennifer L. Murray (jennifer.murray@unf.edu) is Associate Dean, University of North Florida. Daniel E. Feinberg (daniel.feinberg@unf.edu) is Online Learning Librarian, University of North Florida. 
Students had to open a new browser window to access the library and then go back to Canvas to complete their assignments, which involved multiple steps. This caused frustration among students who had to remember the library URL, while also getting used to navigating their new courses in Canvas. Librarians consistently spent large amounts of time instructing students how to navigate to the library website during library instruction sessions and research consultations. In effect, more time was spent with students to guide them to library resources such as programmatic or course specific Springshare hosted LibGuides (also known as library guides), or the library homepage. Rather than being focused on how to use library resources and become more information literate, students spent more time on just locating the library website to get to the UNF library's online resources.

Together, the OLL and Library Director talked about possibilities in Canvas that would benefit all students who attended UNF both in-person and online. Canvas is located in UNF's MyWings, a portal where all students go for coursework, email, and resources that support their academic studies at UNF. It became apparent that if it was possible, there needed to be a quicker way to access the UNF library resources for students.

\section{LITERATURE REVIEW}

With the advent of online learning, it became obvious that students needed to have library access within their online learning management system. For campuses such as UNF, this meant within Canvas. For UNF students that are distance or online students only, this was especially true. Farkas noted that librarians had worked to determine the best ways to provide library materials, services, and embed librarians into the LMS. ${ }^{1}$ Over the last fifteen years, LMS have become more important to support the growth of online learning. Pomerantz noted that the LMS has become critical to instruction and online learning. Approximately 99 percent of institutions adopt an LMS and 88 percent of faculty utilize an LMS platform. ${ }^{2}$ This "puts it in the category with cars and cellphones as among the most widely adopted technologies in the United States." ${ }^{3}$ Library guides that have been integrated into an LMS increased their visibility, but did not guarantee that faculty and students would utilize them. That is why it was critical to continuously collaborate and communicate with faculty, students, and librarians to bring attention to the resources that could assist students. Farkas noted that librarians at The Ohio State University discussed that no matter how the library was integrated into a university's LMS, the usage of the library there was decidedly dependent on if the faculty professor promoted the library to their students. ${ }^{4}$ The reality that libraries faced was that without visibility in an LMS, students that were online/distance learners needed to remember or find the library's website. While this seemed to be inconsequential, it caused students to use Google or other resources instead of their university/college's library discovery tool or library databases.

Farkas noted that Shank and Dewald's seminal article described a university's LMS as having two levels, macro and micro. When there was one way to access the library in the LMS, then it was termed macro. This single pathway allowed for less maintenance since there was a single way to access the library from the LMS. ${ }^{5}$ The University of Kentucky embedded the library by adding a library tab in Blackboard. Other institutions like Portland State University, Ohio State University, and Oakland State University developed library widgets to make the library more accessible. ${ }^{6}$ The addition of library and research guides in library instruction was critical to increase visibility for 
students and furthermore make sure students had easier access to the library through their LMS. Getting librarians' access to the LMS at their institutions is an ongoing issue. ${ }^{7}$

UNF librarians wanted to determine best practices to decide how the library could integrate into Canvas. Therefore, research was needed to see what other university libraries were doing. The librarians at UNF discovered that there was no obvious preference based on examples found in research to accomplish how to get the library into Canvas. Davis observed that "claiming a small amount of real estate in the LMS template ... is an easy way to put the library in students' periphery." By simply having a library link added or a page added to each course was "the digital equivalent for students of walking past the library on the way to class." ${ }^{8}$ However, it seemed that a lot depended on how an LMS was used at an UNF and the technical expertise available. Thompson and Davis noted that the "LMS technology has added another layer of complexity to the puzzle. As technology evolves to address changes in learning design, student and faculty attitudes, expectations, perceptions will continue to be a critical piece of the course integration puzzle." 9

While looking at other institutions, there were a variety of ways in which Canvas and the library were integrated. There were numerous examples from embedded Springshare product library guides, to the creation of modules of quizzes or tutorials, and even to the creation of online minicourses, and embedded librarians in LMS courses. ${ }^{10}$ Penn State University looked at their method of how to add library content into Canvas. They already had a specific way of putting library guides in Canvas, but it was not in a highly visible location for students to easily access. When faculty put guides in their courses, with the collaboration of librarians, the guides were used. However, many of the faculty did not use these librarians or resources. A student survey and user studies were used to best learn how to fix the problem of students and faculty that did not use the guides and content more. Penn State worked with their COMM 190 instructors to administer a survey that was extra credit, to ensure getting responses. ${ }^{11}$ "General findings included: 53 percent of students did not know what a course guide was; 41 percent of students had used a guide for a class project; 60 percent accessed a course guide via the LMS; and 37 percent of students used course guides on their own."12 Many students were interested in doing their library research within Canvas itself. It should be noted that the guides needed to be in a prominent place in Canvas, but not overwhelm the course content. For course-specific guides an introductory statement was needed to describe what the guide was about. When the release of Springshare's LTI tool occurred, it became an optimal time in which the technical solutions allowed for Penn State's library guides to be embedded smoothly into Canvas. ${ }^{13}$ The Learning Tools Interoperability (LTI tool) allows for online software to be integrated into Canvas. In effect, when professors want to add a tool to their course, it allows for more seamless and controlled avenue. In the case of Library Guides, it creates a way in which guides can be embedded into the LMS with little problems.

Another example of a library integration into a campus LMS was at the Utah State University (USU) Merrill-Cazier Library. They looked to find a way to maximize the effectiveness of Springshare's library guides when they assessed the design and reach of library guides within their LMS. ${ }^{14}$ They took a unique approach to build an LTI tool that automatically pulled in the most appropriate library guide when the "Research Help" link in Canvas was activated by a professor. They also saw this as an opportune time to redesign their subject guides and ensure there were guides for all disciplines. They provided usage data to subject librarians to help determine where there might be opportunities to interact with classes and provide more library instruction. Overall, 
the study and feedback they received from students helped them to find ways to improve how librarians used and thought about library guides, and expanded their reach based on usage data. ${ }^{15}$ This ability to add library guides to Canvas provided students a way to access library materials or the library without having to leave the online classroom.

Many libraries have conducted focus groups and usability studies that were key to providing valuable feedback on the knowledge and understanding that faculty and students had of guides, ways to improve information shared that assisted students with their coursework and faculty in their online teaching. Research indicated that exploration and implementation of integrating library guides into an LMS led to a need to improve and provide more consistently designed guides. ${ }^{16}$ The literature indicated the importance of a strong relationship with the department that manages the LMS. These integrations were made much easier when there was a relationship established and it sometimes led to finding out about additional opportunities to integrate more with the LMS.

Penn State saw an increase of over 200,000 hits to its course guides believed to be because of the LTI integration. ${ }^{17}$ This, however, did not guarantee that the students benefited from the course guides, similar to library statistics not proving resources were being used despite page hits. In addition, faculty were able to turn off the LTI course guide tool, which reduced the chances of student usage or awareness of the course guide. Based on feedback from students and faculty, it did not matter where the course guides were since they could be ignored anyway. A Penn state blog was developed by the Teaching and Learning with Technology unit to provide instructors a venue in which they could be aware of online services that librarians provide. 18 "Although automatic integration allows specialized library resources to be targeted at all LMS courses, that does not mean that they'll be accessed. It is important then to build ongoing relationships with stakeholders, providing not just information that such integrations exist, but also reasons why to use them."19

However, not all universities and colleges decided to integrate the library strictly through a library guide or a link to the library integration into their LMS. Karplus noted that students spent more time online rather than going to the physical academic library. Karplus discussed that the digital world combined with academic library resources had two benefits. One of which brought online research as a more normal occurrence. The second benefit was that students were more comfortable with accessing online resources. ${ }^{20}$ While using Blackboard, St. Mary's College's goal was to incorporate library information literacy modules into courses that existed. Using the Blackboard LMS, students were able to access all components of their courses including assigned readings. This became their academic environment. Therefore, information literacy modules, tutorials, and outside internet resources could be added to the LMS. ${ }^{21}$ Tutorials combined with pre- and post-testing, gave faculty instant feedback. Librarians were also able to participate in Blackboard through discussion boards and work with students. ${ }^{22}$ There was a constant need to update the modules and the information added to Blackboard. Librarians having access to the Blackboard site, allowed for students to use the library resources more readily. "The site can be the focal point for many librarians in one location thus ensuring a consistent, collaborative instructional program."23 Overall, the integration of campus librarians into an LMS was to get students to use the library in order to be more successful in their academic endeavors. 


\section{DEVELOPING A PLAN OF ACTION}

Initially, the OLL and Library Director brainstormed possible integration ideas, ranging from adding a library global navigation button to the Canvas UI, to adding a link to the library in the Canvas help menu. At the same time, they also researched what other libraries had done. After brainstorming, it was realized that additional conversations needed to occur within the library and with UNF's Online Learning Support Team, a part of the Center for Instruction and Research Technology (CIRT), the group that manages Canvas. The discussion to integrate the library and Canvas was a complex matter. UNF Administrators asked for a proposal to be written so it could be brought to the library, Online Learning Support Team, and Information Technology Services (ITS) stakeholders for discussion and approval. That proposal, along with much needed discussion, was critical in order to determine the possibilities and actions that needed to be taken. That being said it was important to recognize the importance of what was best to serve the faculty and students.

When brainstorming discussions started to occur with UNF's Online Learning Support Team, it was important for the library to determine what options were available to embed the library in Canvas. The Library had a strong relationship with UNF's Online Learning Support Team and ITS administrators, which made this an easy process to pursue. What the OLL and Library Director initially wanted was to add a simple link to the global navigation in Canvas that would take all users to the library homepage. However, it became apparent that this was not possible due to the fact that this space is limited and many departments on campus would like greater visibility in Canvas. The next option, which was easier to implement, was to add a link to the library homepage under the help menu in Canvas. Although this menu link was added, it was so hidden in Canvas that the OLL and Library Director felt that it would never be found in Canvas by faculty, let alone students.

CIRT administrators asserted to the OLL and Library Director of what other possibilities were available. After researching options, the library recommended creating access to library resources and services using a Springshare LTI Tool for library guides, which CIRT agreed to. Library guides, or LibGuides, are library webpages that are built from Springshare software. Using the LTI tool seemed like a great possibility since it would allow for more of a presence in addition to the help link to the library homepage. After approval from library administration and initial discussions with IT, the project moved forward.

\section{IMPLEMENTATION}

The project took about a year to complete from the time discussions began internally in the library to the time the integration went live (see figure 1). 


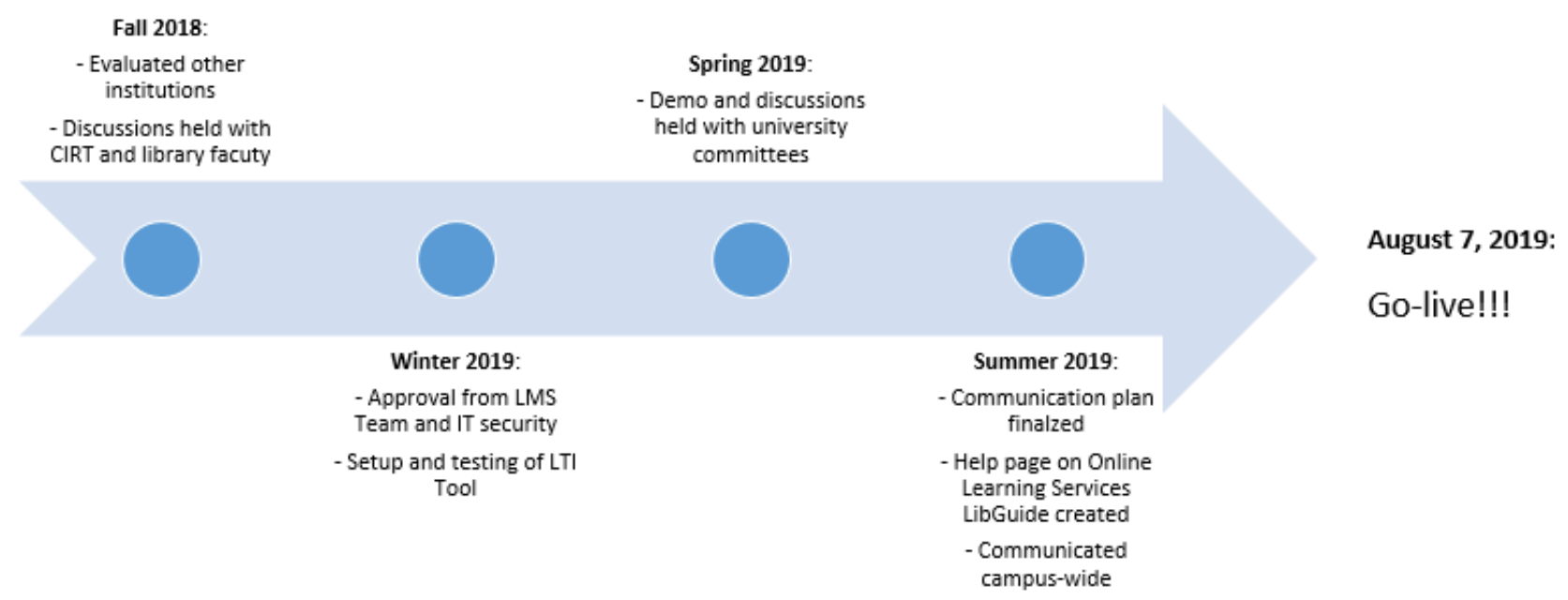

Figure 1. Project Timeline

The idea to have a seamless entryway to the library seemed to be a good idea based on observations and feedback from students, but the OLL and Library Director started by completing an environmental scan to see what other institutions did to get ideas on ways the UNF Library could integrate into Canvas. The OLL and Library Director learned that there were a variety of ways it had been done from the integration of the library at the global navigation level, course level, and by an added link to the library under the help menu in Canvas. It became clear that an integration into Canvas would seem like an obvious progression to strengthen not only online learning, but also give students the ability to benefit from the resources that the library subscribed to and enhance their curricular needs.

Conversations then occurred with UNF's Online Learning Support Team to discuss integration options further. After much discussion, a decision was made to pursue an added link to the library website under the Canvas help menu and a new LTI tool at the course level. Since Canvas was used in so many courses, it was determined that university-wide campus committee agreement was needed on how to go about adding library guides to Canvas courses.

Librarians were also approached at this time to get their input and feedback. The goal seemed obvious to the librarians. When they were approached, buy-in to support the students with Canvas by way of the help button and LTI tool integration seemed more than straightforward. Therefore, for the librarians, the goal was to solve the problem of making sure that students could easily access library materials. Overall, the library faculty's preference for the implementation was to embed the library website under the Canvas help menu while also have the Student Resources LibGuide inside all Canvas courses using the Springshare LTI tool. After all internal approvals were obtained, the link to the library was seamlessly added under the Canvas help menu. As for the Springshare LTI tool, it required more work and discussion before it could be implemented.

After approval was granted from the UNF Online Learning Support Team and campus ITS Security Team, the integration began. Configuration options for the LTI tool were explored and the Systems and Digital Technologies Librarian worked closely with the UNF Online Learning Support Team and Springshare to setup the LibApp LTI tool. 
The first step was to configure Springhare's Automagic LTI Tool to automatically add LibGuides to courses in Canvas. This included adding an LTI Tool Name and Description, which appeared in Canvas during setup and the course navigation. It was also decided to set the Student Resources LibGuide as the default guide for all courses based on feedback from across campus. Instructors could request to use a different LibGuide for their course. To enable this, two parameters had to be set in the Automagic LTI Tool to enable LibGuide matching between Canvas and LibGuides:

- LTI Parameter Name: For UNF, this was set to "context" label, to select the course code field in Canvas.

- LibGuides Metadata Name: This was set to the appropriate value to identify the metadata field used in LibGuides.

If an instructor decided to change the default guide to another guide, these two parameters would need to be entered into a specific LibGuide's Custom Metadata, so that Canvas could link to the designated guide to display in a course. The change had to be made in the LibGuide itself, so it was handled by the Systems and Digital Technologies Librarian. There had not been many instructors who had requested this yet, but if utilized, the library would also have had to ensure this carried over each semester by updating the metadata in the guide to the new course code.

After the configuration was completed on the Springshare side, the next step was to set up the integration in the Canvas test environment. An external application had to be installed in Canvas to allow the Springshare LTI tool to run. After it was tested, the application was applied across all courses and set to display by default, which the majority of faculty preferred. Faculty who did not want to use the integration had the ability to manually turn it off in Canvas.

During the implementation setup, a few minor issues were encountered. After seeing what the Student Resources Guide looked like in Canvas it became clear that the header and footer were not needed and just cluttered the guide. They were both removed in the LTI Setup Options to ensure a cleaner looking guide. Since the LibGuides were being embedded into another system (Canvas), formatting of the guides had to be adjusted. The other issue encountered was trying to add available Springshare widgets such as the library hours or room booking content to the guide using the Automagic LTI Tool. While this was not successful, it was determined that the additional options were not needed.

Once the integration was set up in the Canvas test environment, demonstrations were held and input was gathered from stakeholders through campus-wide meetings with faculty to obtain their input. It was critical to determine if faculty would utilize LibGuides in their Canvas courses. An overview of the integration and the benefits were given to the Campus Technology Committee and Distance Learning Committee faculty. A demonstration was also given so that these faculty committees could see what the integration would look like in their courses. Overall, the feedback obtained from the faculty was very positive. The preference was to have the configuration be optout, where the library guides would automatically display in Canvas courses. Many faculty members were excited about the integration and looked forward to having it in their courses.

After demos took place and final setup was completed based on feedback, the integration was then setup in the Canvas production environment and was announced via newsletters, emails, and social media. As of the fall 2019 semester, the library's Student Resources Guide was integrated into all courses in Canvas (see figure 2). 


\section{CIRT.TOL-SUMMER2019 ; CIRT.TOL-SUMMER2019}

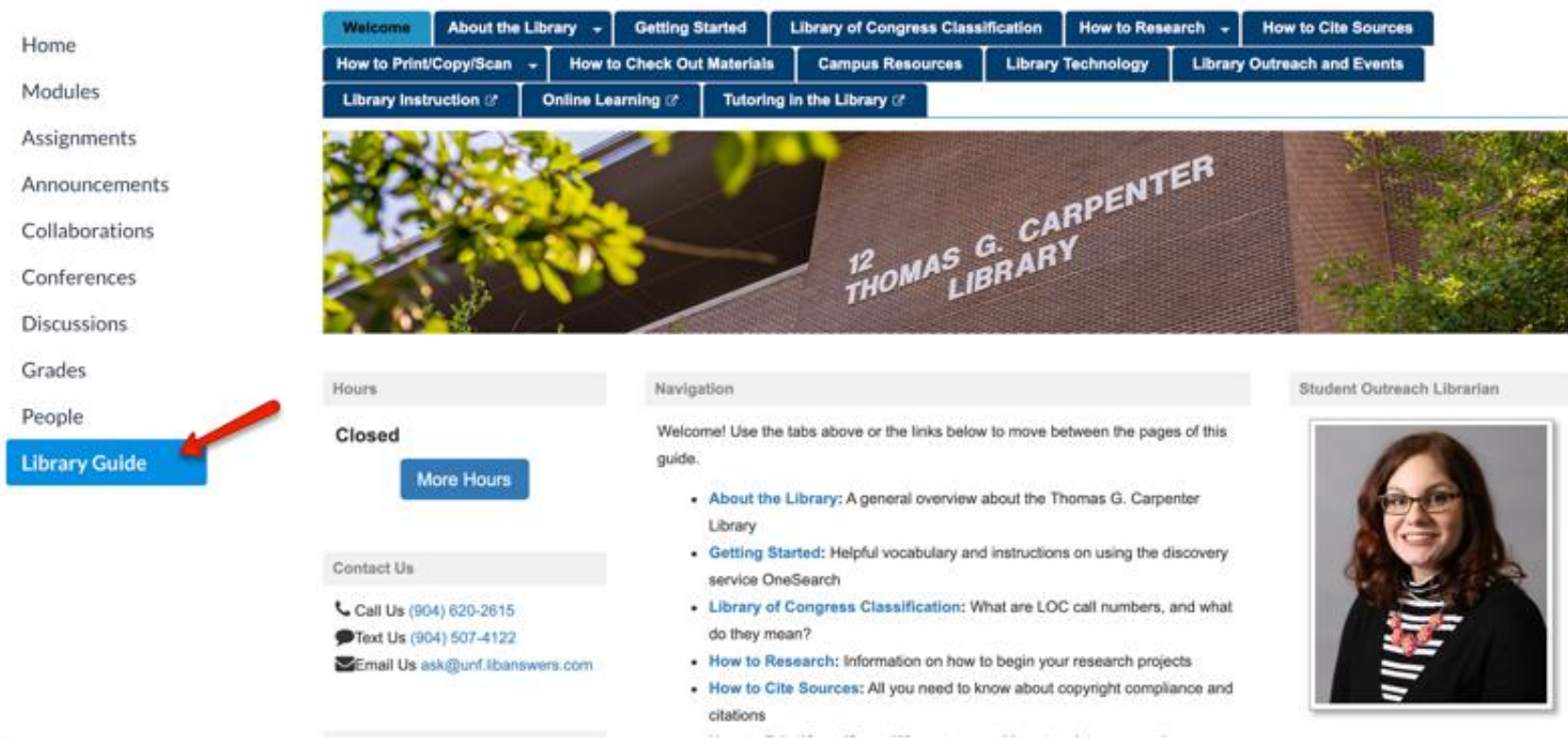

Figure 2. Student Resources Library Guide in Canvas

\section{BENEFITS OF THE INTEGRATION}

Students are dependent on their campus LMS in order to complete their coursework, support their studies, and in the case at UNF, have easier access to the online campus. The LibGuide integration not only streamlined their way to library resources, but also promoted library usage from students that may not have known how to get to the resources available to them. For faculty it should be noted that they were able to replace the default student LibGuide with a more specific subject or course guide. Either way, it brought more awareness to resources and services that supported curricular needs. The Springshare chat widget in the guide also gave students the ability to communicate directly with a librarian from within Canvas. This integration not only increased the library visibility in the online environment but enabled all students, whether inperson, hybrid, or online, with direct access to the resources they needed for their coursework.

\section{CHALLENGES OF THE INTEGRATION}

Although there were many benefits to integrate the library into Canvas, there were many challenges with making the integration happen. There were many more stakeholders than expected. From library administration, to the Canvas administrators, to library faculty, and teaching faculty committees, their input was needed prior to the project taking place. Since the project grew organically, this meant that all of the stakeholders were brought in as the project grew or unfolded. Once the project received approval from the library and CIRT administrators, ITS administrators had to give the final approval in order to proceed with the integration of library guides. The process to implement the integration took some time to figure out. In addition, getting buy-in from the teaching faculty was key as the navigation options in their Canvas courses would be impacted. Making sure the faculty understood how it would assist their students was important as the goal was to help their students succeed with their coursework. 
A concern was if faculty would tell their students, or conversely, would students find the link to the LibGuide on their own? Determining how the news of the library and Canvas integration would be communicated to the UNF community was the final step. The Library Director, OLL, and CIRT administrators needed to determine the best communication routes to get the UNF community aware of this news. In effect, emails, UNF updates/newsletters, and by word of mouth by teaching faculty. It was crucial that students be aware of these tools. This meant that going forward, UNF would depend on word of mouth or student's curiosity in the Canvas navigation bars themselves.

\section{DISCUSSION AND NEXT STEPS}

Integrating the library with the UNF's Learning Management System, Canvas, took much planning and collaboration, which was key to creating a more user-friendly learning environment for students. In reflecting on what went well and what did not, the UNF librarians learned several important lessons that will help improve upon the implementation of future projects.

To begin, it is important to identify and involve stakeholders early on, so they can provide feedback along the way. Getting buy-in from the teaching faculty is also key since the integration affects the navigation options in their Canvas courses. For UNF, initially, the OLL and Library Director did not realize how many groups of teaching faculty and departments would need to approve this Canvas change and implementation. It was important to have them understand the importance of the integration and how it can assist their students with their coursework. Considering the content of the library guides was important because of the impact it would have on Canvas courses. For example, at the UNF Library some students thought that the librarian's picture on the default guide was in fact their professor. In turn, students began to contact her. This caused much confusion for our students and professors alike.

Along the way, communication is critical so that everyone is kept informed as the integration progresses. Communication at the appropriate times and ensuring all information is gathered about configuration options before starting conversations with stakeholders is important too. Having this transparency at the appropriate times and ensuring there was enough information about the configuration options before starting conversations with stakeholders was important too. Finally, investigating the ability to retrieve usage statistics from day one would be extremely beneficial and provide data to assess how often the library guides are being used in the LMS and by whom. This information would help determine next steps and explore other potential integration opportunities. At UNF, the librarians were not able to implement statistics as part of our integration which has made it more difficult to assess the usage of the library guides in Canvas.

Now that the integration has been completed, ensuring the integration continues to meet the needs of faculty and students will be important. Feedback will need to be gathered from stakeholders to find out if they find the integration useful, if there are any issues being encountered, and/or if they have any recommendations for ways to enhance the integration. Usage statistics will also be gathered as soon as they are available. This will provide information on which instructors are using the library guides in their courses and which instructors are not using them. For those who have used it, it will be an opportunity to target those courses for instruction. For those who have not used them, it will be an opportunity to find out why and make sure they are aware of the benefits of using them in their courses. 
Exploring other integration possibilities, especially as the technology continues to evolve, will be important to ensure the library continues to reach students. While the natural progression of the UNF integration would be to embed librarians in the Canvas platform, others have faced challenges. "According the Ithaka S \& R Library Survey 2013 by Long and Schonfeld, 80-90 percent of academic library directors perceive their librarians' primary role as contributing to student learning while only 45-55 percent of faculty agree librarians contribute to student learning." 24 Even though this is a challenge, faculty collaboration with librarians is crucial for the embedded librarian role. Without a requirement of embedded librarianship, marketing for the librarians and what they can do for students will be essential for their role to be successful. ${ }^{25} \mathrm{At}$ UNF, conversations will have to be held to determine what other integrations would be of interest and possible at our university.

The UNF Library will also be looking to improve the design and layout of library guides. Now that their visibility has increased, it will be important to standardize them and ensure they all have a consistent look and feel, which will make it easier for students to find the information and resources they are looking for.

\section{CONCLUSION}

In today's rapidly changing technological world, it is critical to make resources available despite where students are physically located. Integrating the library's LibGuides into Canvas not only brought more visibility to the library, its resources, and its services, but it also brought the library to where the students were engaged with the university. As noted by Farkas, "positioning the library at the heart of the virtual campus seems as important as positioning the library as the heart of the physical campus." ${ }^{26}$ Providing resources to students at their point of need, enabled them to easily access the information they needed to help them succeed in their courses. It also allowed faculty to integrate library resources that were most beneficial to their courses and enhanced their teaching as well as the educational needs of their students.

The UNF Library will continue to look at how library resources are used, and how to best serve the online community going forward. It will be important to explore ways to enhance existing services with existing technology but also look ahead and determine what may be possible down the road with new and upcoming technologies. In addition, assessing how the library connects to online learners and gathers feedback from students and faculty will be critical to contributing to the success of students.

\section{ENDNOTES}

${ }^{1}$ Meredith Gorran Farkas, "Libraries in the Learning Management System," American Libraries Tips and Trends (Summer 2015), https://acrl.ala.org/IS/wpcontent/uploads/2014/05/summer2015.pdf.

${ }^{2}$ Jeffrey Pomerantz et al., "Foundations for a Next Generation Digital Learning Environment: Faculty, Students, and the LMS" (Jan 12, 2018): 1-4.

${ }^{3}$ Pomerantz et al., "Foundations for a Next Generation Digital Learning Environment."

${ }^{4}$ Farkas, "Libraries in the Learning Management System." 
${ }^{5}$ Farkas, "Libraries in the Learning Management System."

${ }^{6}$ Farkas, "Libraries in the Learning Management System."

${ }^{7}$ Farkas, "Libraries in the Learning Management System."

${ }^{8}$ Robin Camille Davis, "The LMS and the Library," Behavioral \& Social Sciences Librarian 36, no. 1 (Jan 2, 2017): 31-5, https://doi.org/10.1080/01639269.2017.1387740.

${ }^{9}$ Liz Thompson and Davis Vess, "A Bellwether for Academic Library Services in the Future: A Review of User-Centered Library Integrations with Learning Management Systems," Virginia Libraries 62, no. 1 (2017): 1-10, https://doi.org/10.21061/valib.v62i1.1472.

10 Davis, "The LMS and he Library."

${ }^{11}$ Amanda Clossen and Linda Klimczyk, "Chapter 2: Tell Us a Story: Canvas Integration Strategy," Library Technology Reports 54, no. 5 (2018): 7-10, https://doi.org/10.5860/ltr.54n5.

12 Clossen and Klimczyk, “Chapter 2," 8.

${ }^{13}$ Clossen and Klimczyk, “Chapter 2,” 8.

${ }^{14}$ Britt Fagerheim et al. "Extending our Reach," Reference \& User Services Quarterly 56, no. 3 (2017): 180-8, https://doi.org/10.5860/rusq.56n3.180.

15 Fagerheim et al., "Extending our Reach,” 187.

${ }^{16}$ Fagerheim et al., "Extending our Reach,” 188.

${ }^{17}$ Amanda Clossen, “Chapter 7: Ongoing Implementation: Outreach to Stakeholders," Library Technology Reports 54, no. 5 (2018): 28.

18 Amanda Clossen, “Chapter 7,” 29.

${ }^{19}$ Amanda Clossen, “Chapter 7,” 29.

${ }^{20}$ Susan S. Karplus, "Integrating Academic Library Resources and Learning Management Systems: The Library Blackboard Site," Education Libraries 29, no. 1 (2006): 5, https://doi.org/10.26443/el.v29i1.219.

${ }^{21}$ Karplus, "Integrating Academic Library Resources and Learning Management Systems.”

${ }^{22}$ Karplus, "Integrating Academic Library Resources and Learning Management Systems.”

${ }^{23}$ Karplus, "Integrating Academic Library Resources and Learning Management Systems.”

${ }^{24}$ Beth E. Tumbleson, "Collaborating in Research: Embedded Librarianship in the Learning Management System," Reference Librarian 57, no. 3 (Jul, 2016): 224-34, https://doi.org/10.1080/02763877.2015.1134376. 
${ }^{25}$ Tumbelson, "Collaborating in Research."

${ }^{26}$ Farkas, "Libraries in the Learning Management System." 